\title{
Student Centred Design of a Learning Analytics System
}

\author{
Ed de Quincey \\ Keele University \\ Staffordshire, UK \\ e.de.quincey@keele.ac.uk \\ Theocharis Kyriacou \\ Keele University \\ Staffordshire, UK \\ t.kyriacou@keele.ac.uk
}

\author{
Chris Briggs \\ Keele University \\ Staffordshire, UK \\ c.briggs@keele.ac.uk \\ Richard Waller \\ Keele University \\ Staffordshire, UK \\ r.i.waller@keele.ac.uk
}

\begin{abstract}
Current Learning Analytics (LA) systems are primarily designed with University staff members as the target audience; very few are aimed at students, with almost none being developed with direct student involvement and undertaking a comprehensive evaluation. This paper describes a HEFCE funded project that has employed a variety of methods to engage students in the design, development and evaluation of a student facing LA dashboard. LA was integrated into the delivery of 4 undergraduate modules with 169 student sign-ups. The design of the dashboard uses a novel approach of trying to understand the reasons why students want to study at university and maps their engagement and predicted outcomes to these motivations, with weekly personalised notifications and feedback. Students are also given the choice of how to visualise the data either via a chart-based view or to be represented as themselves. A mixed-methods evaluation has shown that students' feelings of dependability and trust of the underlying analytics and data is variable. However, students were mostly positive about the usability and interface design of the system and almost all students once signed-up did interact with their LA. The majority of students could see how the LA system could support their learning and said that it would influence their behaviour. In some cases, this has had a direct impact on their levels of engagement. The main contribution of this paper is the transparent documentation of a User Centred Design approach that has produced forms of LA representation, recommendation and interaction design that go beyond those used in current similar systems and have been shown to motivate students and impact their learning behaviour.
\end{abstract}

\section{CCS CONCEPTS}

- Human-centered computing $\rightarrow$ Visualization application domains; HCI design and evaluation methods.

Permission to make digital or hard copies of all or part of this work for personal or classroom use is granted without fee provided that copies are not made or distributed for profit or commercial advantage and that copies bear this notice and the full citation on the first page. Copyrights for components of this work owned by others than ACM must be honored. Abstracting with credit is permitted. To copy otherwise, or republish, to post on servers or to redistribute to lists, requires prior specific permission and/or a fee. Request permissions from permissions@acm.org.

LAK'19, March 4-8, 2019, Tempe, Arizona, USA

(C) 2019 Association for Computing Machinery.

ACM ISBN 978-x-xxxx-xxxx-x/YY/MM...\$15.00

https://doi.org/TBC

\section{KEYWORDS}

Learning Analytics, User Centred Design, Visualisation, Usability, User Experience, Laddering

\section{ACM Reference Format:}

Ed de Quincey, Chris Briggs, Theocharis Kyriacou, and Richard Waller. 2019. Student Centred Design of a Learning Analytics System. In Proceedings of International Conference on Learning Analytics and Knowledge (LAK'19). ACM, New York, NY, USA, 10 pages. https://doi.org/TBC

\section{INTRODUCTION}

Traditionally a student's progress and level of engagement has been measured by assessment and physical attendance. However, in a student's day-to-day interactions with a University, other real-time measures are being generated and stored e.g. Virtual Learning Environment (VLE) interaction, Library and Online Journal usage etc.. Higher Education (HE) though has traditionally been inefficient in its data use [13]. Learning Analytics (LA) though has the potential to identify at-risk learners and provide intervention to assist learners in achieving success [14].

Examples of large-scale systems that support elements of LA include the University of Southampton's "Student Dashboard"; the Open University's Anywhere app; the University of Bedfordshire's student engagement system; London South Bank University's partnership with IBM [17]; Purdue University's Course Signals [1]. A detailed review of systems has been published by JISC [22], who are currently in collaboration with 50 Universities to build a learning analytics service for the UK HE sector.

Increasingly, student data is being aggregated and presented to tutors and students in the form of a Dashboard. As part of a review by [3], 44 existing LA systems were identified from the literature, with the majority (34) being targeted at lecturers or teachers. Of the LA systems that were designed to be used by students, there were very few examples of them being co-developed with students. Similarly, [21] found that the majority of systems are instructor facing $(74 \%)$ in a HE context, and researchers do not conduct much research on the impact of these systems on teaching and learning.

A more recent paper by [2] has comprehensively reviewed the literature for "student-facing learning analytics reporting systems that track learning analytics data and report it directly to students". They found 94 articles containing student-facing examples with only $6 \%$ including some form of user needs assessment and only $13 \%$ of articles discussing the visual or recommendation design process. Only $10 \%$ of articles reported a usability test on the system. 
They also found that only $17 \%$ of articles contained a visualisation component and a recommendations component, with the majority of forms of visualisation being standard charts i.e. bar, line and tables. They concluded that considering needs assessment, information selection, visual design, and usability testing will "greatly enhance the rigor of the design and development process in studentfacing learning analytics reporting systems research" [2].

This paper therefore describes a HEFCE funded project that aimed to co-develop a LA system with students that shares their own data directly with them in real-time, using visualisation methods that motivate and personalise their learning experience. The LA system was then incorporated into the delivery of 4 Undergraduate modules with the key goals of increasing engagement, making the VLE a more active space for learning and teaching and bridging the gap between physical and digital spaces. A mixed-methods approach was then used to evaluate the usability and impact of the LA system on student engagement and learning. Taking the recommendation from [2], this paper outlines the analysis, design, development, deployment and evaluation of the system, not just a description of the final product.

\subsection{Related Recent Work}

Since the publication of [2] there have been other papers that have started to explore Student Facing LA and have reiterated the need for more user involvement in the development and evaluation of these systems.

[9] conducted a systematic literature review which analysed the extent to which theories and models from learning sciences have been integrated into the development of student facing LA dashboards. They found that "very few dashboard evaluations take into account the educational concepts that were used as a theoretical foundation for their design". They also suggest that comparison with peers was not perceived positively by all learners. They recommend that the focus of an LA dashboard should be not only on its goals but also the impact on learners' motivation and its usability. They also suggest that whether learners understood the data should be evaluated, how much they agreed with it and how they interpreted it.

[4] have suggested that LA experts may need to "look beyond themselves and their own perspectives and expertise to innovate LA platforms and interventions". They recommend that by co-creating with the users of LA, usability and usefulness can be improved as well as a greater understanding from LA interventions achieved. They have identified a number or barriers to LA including a mismatch between current design and the capacity of students to engage with the platform e.g. due to lack of data literacy.

It is clear therefore that there is a current need for more research into both the co-creation of student facing LA systems and also a more comprehensive evaluation of their usability and impact on the learner.

\section{ANALYSIS AND DESIGN}

In order to determine students' understanding of LA, potential forms of visualisation, functionality and overall interaction design, a version of the User Centred Design (UCD) methodology was followed
[24]. The process was iterative and involved users during the analysis, design and development phases via a combination of knowledge elicitation and user research methods. To facilitate this, $4 \mathrm{stu}-$ dent ambassadors were recruited and trained as user experience researchers. They were then tasked with recruiting students and applying these methods under the supervision of experienced members of staff from the project team. The following sections describe the various stages that were undertaken.

\subsection{Identifying Motivators via Laddering}

In order to identify suitable visualisation techniques and motivational metaphors to be incorporated into the LA system, an interview technique called laddering was used. Laddering is a method initially developed by [8] and uses probes to acquire requirements and selection criteria in an explicit, semi-structured form [19]. Laddering has been shown to be particularly good at uncovering unexpected higher-level goals and motivations which would be missed by standard interviewing techniques [19].

A laddering session usually starts with a choice between two arbitrary items with the respondent being asked "Which of these would you prefer and why?". Following this choice, the interviewer attempts to "ladder up" by asking follow on questions such as "Why would you prefer ....?" or "Why is .... important to you?".

For the initial probes for the laddering sessions, the student ambassadors identified from the literature (17 papers reviewed) what motivates students to study in HE:

(1) Being the best you can be/Effort

(2) Build self-confidence

(3) Career/Vocation/Job prospects

(4) Industry

(5) Giving yourself options

(6) Grades/Marks/Qualifications

(7) Mastery of a subject/Interest in Subject/Stretch themselves intellectually

(8) Mentoring/Family

(9) Money

(10) Part of a Professional community

(11) Self-efficacy/ Helplessness (the opposite of self-efficacy)

(12) Sense of connectedness with others with similar goals/ Success as a group of peers

(13) Social Prestige/Recognition

Paired images representing these motivators were then used as the focus of laddering sessions with 10 students studying a range of different subjects, organised and run by the student ambassadors.

From the 10 sessions, images representing each of the 13 motivators were used, meaning that in total 130 individual "ladders" were completed. An example is shown in Figure 1. The ambassadors then provided transcripts (using the notation recommended by [18]) from these interviews which were analysed by the authors for common themes. Although there was overlap with those found in the initial literature review, a further 8 motivators were elicited:

(14) Supporting family/Home life

(15) Negative imagery

(16) Rising above circumstances

(17) Financial security

(18) Controlling own destiny 


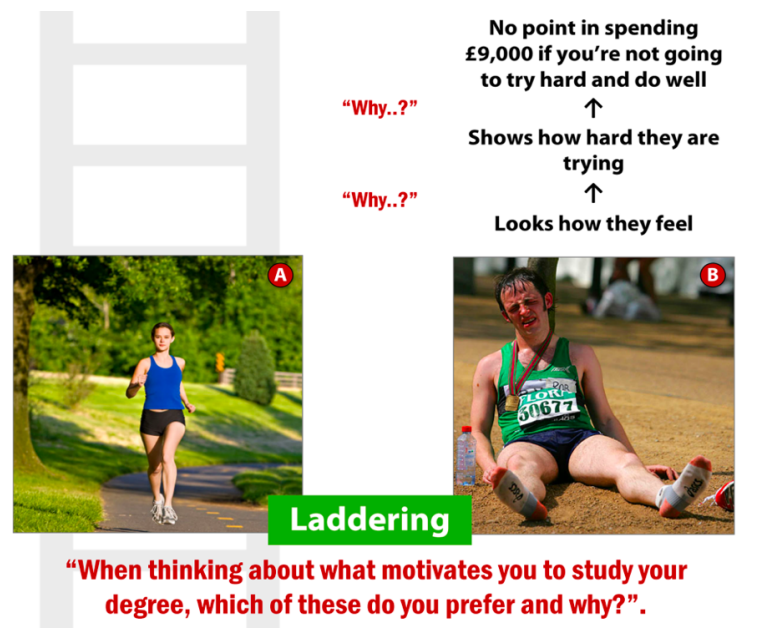

Figure 1: Illustrative example of how a laddering exercise leads a student to reveal a core value that that they hold about a given motivation to study

(19) Individuality

(20) Opportunity to travel

(21) Fear of wasting University opportunity

Interestingly, negative motivators related to fear and failure were elicited as well as a sense of wanting to rise above current circumstances and broaden opportunities; both perhaps representing the types of students recruited for the sessions.

During the analysis, it was clear however that there was overlap between these motivators e.g. "Money" and "Financial Security", both relating to "Money", and these were then aggregated by the authors (using a basic version of Open card sorting [23]) into 9 final motivators: Career/Industry; Money; Attainment; Mastery; Options; Professional community; Family; Self-development and Fear of failure.

\subsection{Visualisation Design via Focus Groups}

The student ambassadors were then asked to contribute to a shared Pinterest board ${ }^{1}$ with examples of visual design that they felt would be appropriate for their peers. In collaboration with an external graphic design company, the motivators, these examples and findings from a previous study [3] (which asked 82 second year Computer Science students to design LA dashboards) were then used to produce some initial design ideas for how LA data could be visualised for both "web" interfaces and email (see Figure 2).

The aims for these visualisations were to try and create a common visual theme encompassing the motivators e.g. icons, to avoid the use of standard visualisation techniques and to act as a focus for future user research sessions. The two metaphors within the initial designs related to:

(1) A fractal tree, so that each join is a node holding a "nut" representing each motivation that could be collected.

\footnotetext{
${ }^{1}$ https://www.pinterest.co.uk/thegreendruid/learning-analytics-visualisations/
}

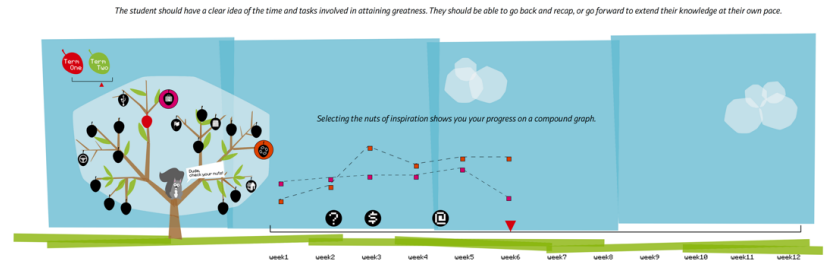

Figure 2: Timeline visualization with a student's progress represented by a tree metaphor

(2) A timeline which students could interact with and see how their motivation scores change week on week (the main finding from [3]).

These mock-ups then formed the basis of 6 Focus Groups (based on the recommendations from [11]) with a further 20 students, again planned, organised and run by student ambassadors. In these sessions, participants were first of all given an overview of the project and then paper and pens, the list of motivators and asked to draw the first thing that came to mind for each motivator. This was to see whether the icons designed in the mock-ups were similar/recognisable to those expected by the students. Then, students were shown the mock-ups themselves and guided through a number of questions related to whether they understood the metaphors used; the general look and feel; whether they would use it; whether there were any other forms of representation that could be used and whether they understood how their own personal data would feed into the visualisations

2.2.1 Findings from Focus Groups. Transcripts from all Focus Groups were then created and common themes identified (again in line with [11]) Overall it was clear that students saw the motivators as goals i.e. things to aim for that would motivate them, personalisation was important and that they preferred academically focused motivators. The detailed findings were as follows:

(1) The motivator meanings aren't concrete. They can mean different things to different students.

(2) Students struggled to understand how their data related to non-academic specific motivators.

(3) The general consensus was that the University VLE was the best platform for viewing the visualisation but that an emailer would be a handy reminder and a useful "at-a-glance" way of seeing how they were doing.

(4) There was a clear separation between students who liked the playful aspect of the tree metaphor and students who would prefer a more formal/traditional presentation for the visualisation.

(5) The tree metaphor and visual feel were generally well received but students came up with ideas that related to a far more personalised representation of the student themselves e.g. avatars and pictures of the student surrounded by their motivators.

(6) On the email, a percentage change would be more important than just seeing a score for each motivator.

(7) Students should be able to select motivators that have the most meaning to themselves. 
Table 1: Metaphors used to represent motivator scores

\begin{tabular}{lll}
\hline Motivator & Icon & Image (and Scale) \\
\hline Career/Industry & Building & $\begin{array}{l}\text { Lanyard with different job lev- } \\
\text { els (Intern -> CEO) }\end{array}$ \\
\hline Money & Cash & Car (“Old banger” -> Sports) \\
\hline Attainment & Trophy & Fail, 3rd, 2:2, 2:1, 1st \\
\hline Mastery & Books & Books (Single -> Many) \\
\hline Options & Signpost & $\begin{array}{l}\text { Buildings (Single building } \\
\text { showing a company logo } \\
\text { airport) }\end{array}$ \\
\hline $\begin{array}{l}\text { Professional } \\
\text { community }\end{array}$ & Handshake & $\begin{array}{l}\text { Phone conversation bubbles (to } \\
\text { show connectedness) }\end{array}$ \\
\hline Family & House & Abode (small -> castle) \\
\hline $\begin{array}{l}\text { Self- } \\
\text { development }\end{array}$ & Certificate & $\begin{array}{l}\text { Hobbies (bike, tennis racquet, } \\
\text { gardening etc.) }\end{array}$ \\
\hline Fear of failure & Trapdoor & Trapdoor (Closing -> Opening) \\
\hline
\end{tabular}

(8) Reminding under-achieving students of poor scores against their motivators is likely to de-motivate the student.

(9) There was another clear separation between competitive students and non-competitive students. The former liked the student comparison visualisation. The latter did not. (In line with the recommendation from [9])

(10) Anonymity is probably important in any student comparison visualisations.

The main conclusion from the focus groups was that the initial metaphor suggested, a branching tree that grew with the student's progress, was for some students too childish and for some too abstract. It became clear that students either wanted a far more professional view of their data e.g. an infographic style CV containing standard charts, or to be represented as themselves e.g. an avatar in a world where their progress was shown as what their life and career would be (which we termed the personified view). In order to deal with this conflicting feedback, a form of personalisation was designed, described in the following section.

2.2.2 Professional and Personified Visualisations. Following the Focus Groups, a second set of iterative designs were made for the two representations identified (based on the student feedback and the drawings they created). For the professional view, an icon was created for each motivator to be used in a standard chart visualisation and throughout the LA system. For the personified view, a set of images was created for each motivator based on a 5-point scale. Table 1 shows the icon metaphor chosen for each motivator along with the image that can be represented on a scale.

Figure 3 shows three example motivators and the set of five images that were designed to represent them on a scale from 1 to 5 ( 5 being the highest score).

Figure 4 shows the first version of the personified theme. Students are required when signing up to the system to choose up

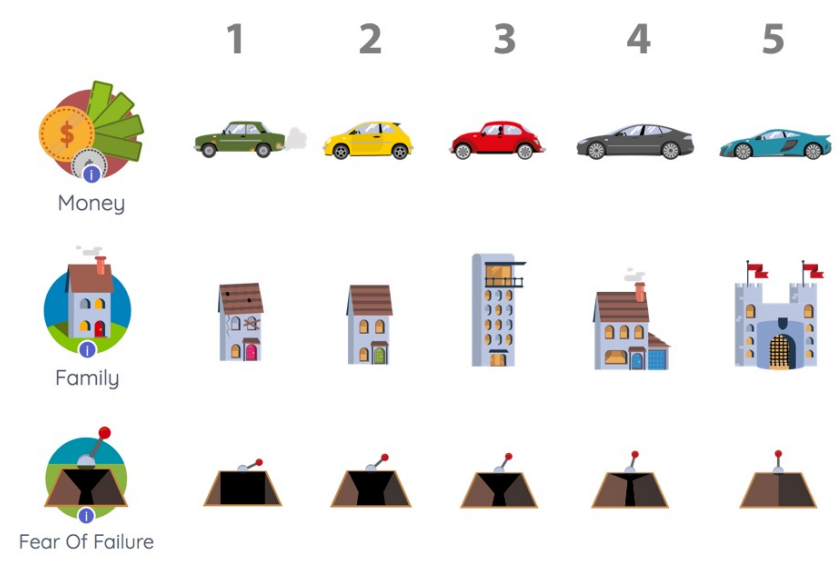

Figure 3: Visualising motivator scores as a scale

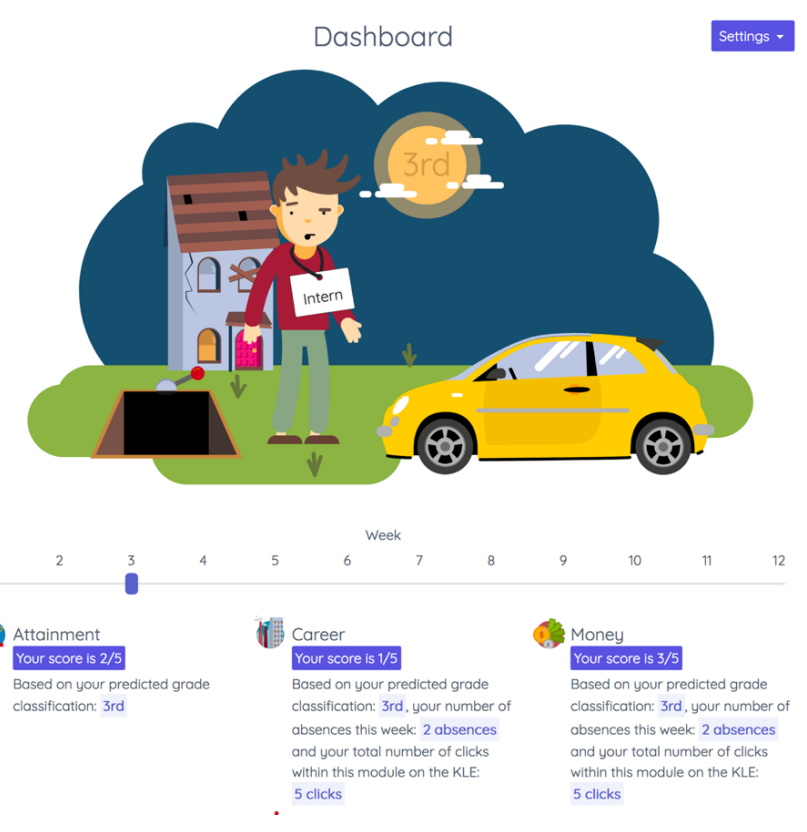

Figure 4: Version 1 of the "personified" theme

to 5 things that motivate them to study and the visualisation is then composed of a set of images that both represents the chosen motivators and their current scores. Students can use the slider underneath to scroll back and forth through each week as a module progresses. They are also given a breakdown for each motivator, explaining what their score is for that week and why. At any time, they can change motivators and themes (for the final professional style visualisation, see Figure 6).

For further personalisation, during sign-up students are also given the opportunity to create a simple avatar to represent themselves in the system, shown in Figure 5. 


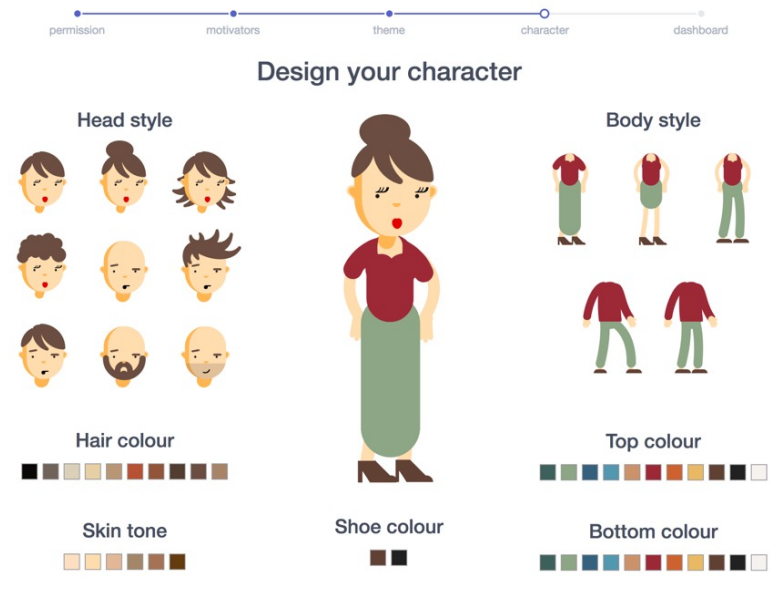

Figure 5: Avatar creator on the "personified" theme

\subsection{Design via Contextual Interviews}

The first version of the LA tool was launched in October 2017 on 2 first semester modules (see Section 4 for more details). After the end of the semester, 10 one-on-one evaluation sessions were carried out in collaboration with the student ambassadors, to gather further feedback on the tool and its design. During these sessions, students were asked to sit down in front of an example LA dashboard (from sign-up to the visualisation screen) and were asked to think aloud whilst using it. If not covered by the participant during the think aloud, questions were asked related to whether the student understood the relationship between the motivator graphics and their data/scores; the motivators' meanings; how much they trusted the underlying data and calculated scores; how they would feel if they received a negative report and whether it would encourage them to improve, and what criteria would they want to see used in a comparison chart. The transcripts of these sessions were analysed by the project team with the majority of students being positive about the concept and could see how they would use it to improve their learning. Common themes identified included:

(1) The privacy policy was generally ignored (which students were shown at sign-up of the system).

(2) The timeline/slider was not very visible and not interacted with.

(3) The link between the data visualisation and the motivator descriptors was too "fuzzy".

(4) The bar chart made more sense than the radar chart in the professional theme (users were given the option to switch between both).

(5) A clear explanation of how to improve a particular score is needed i.e. recommendations.

Enhancements to the system were then made and are shown in Figures 6, 7 and 8 .

A simple "comparison with peer's" visualisation was then also added to the bottom of both themes (following comments made during the Focus Groups) which compared the student's data for various features (not the scores) to the class average (e.g. attendance, views of lecture capture videos etc).

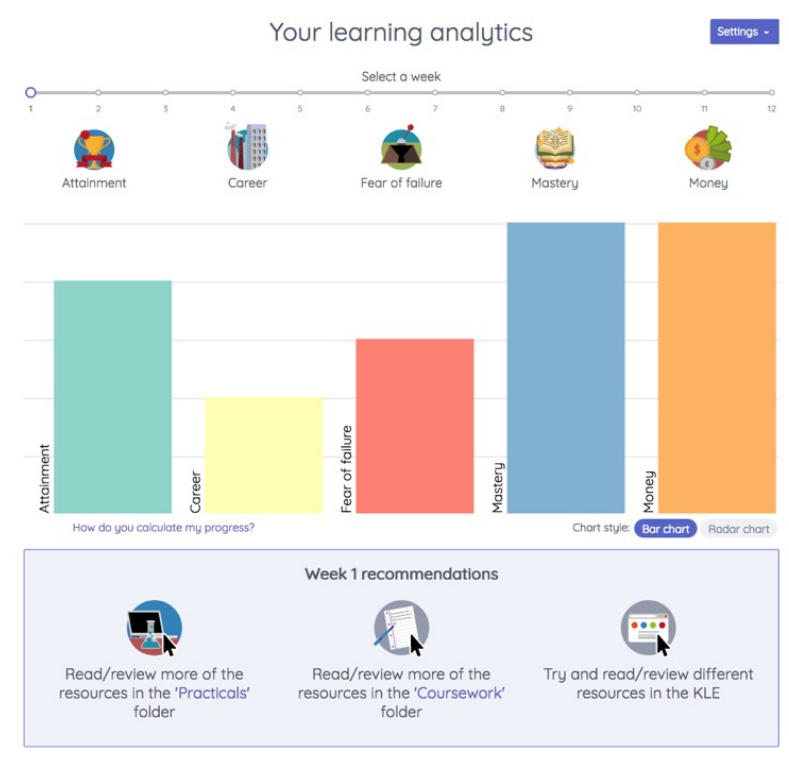

Figure 6: Final version of the "professional" theme showing the timeline at the top, the choice of motivators and associated scores and the recommendations (hyperlinked to the relevant areas on the VLE)

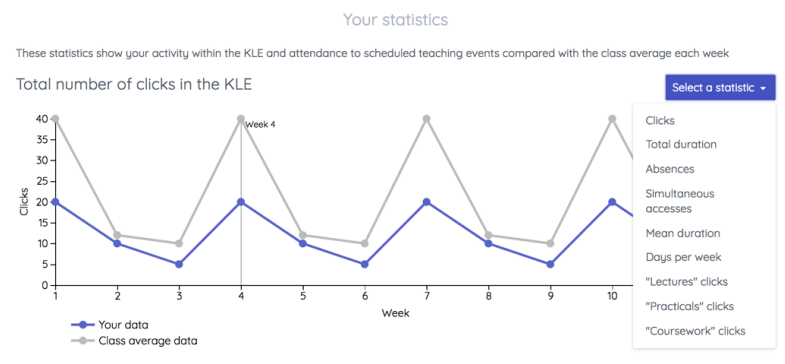

Figure 7: Comparison with peer's visualization

\section{IMPLEMENTATION}

A detailed description of the analytical part of the LA tool is beyond the scope of this paper but the data used and feature set derived based on the data readily available at the university and also on our previous explorations into similar types of data [3]. The LA system itself is powered by machine learning models (Decision Trees) that were trained using python and the scikit-learn library. The back end of the system uses python and flask and nginx to serve a GraphQL API, used by the front end. The interface is built with JavaScript and the react/redux libraries. The system used the university's single sign on solution and was integrated into the VLE (Blackboard) via iFrames (available to students via a link in each module's VLE homepage). The interface was responsive and optimised to work on both desktop and mobile devices.

Table 2 shows the source of the data and the features that were used to build a model of student activity from the previous year's cohort. 

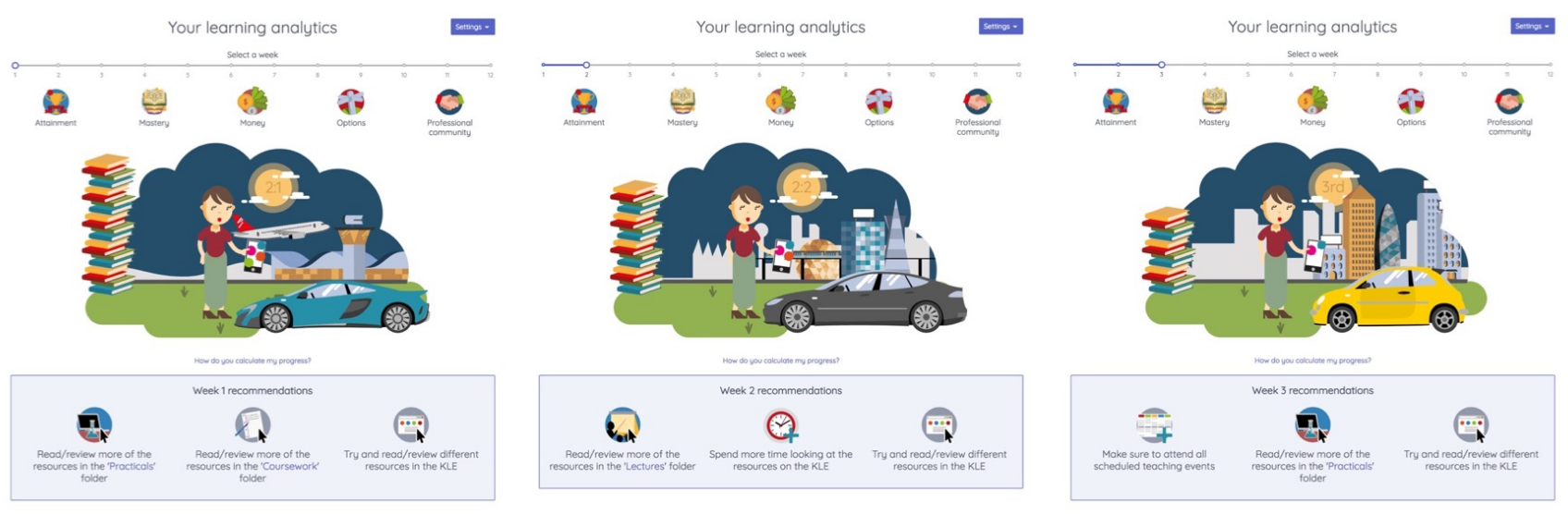

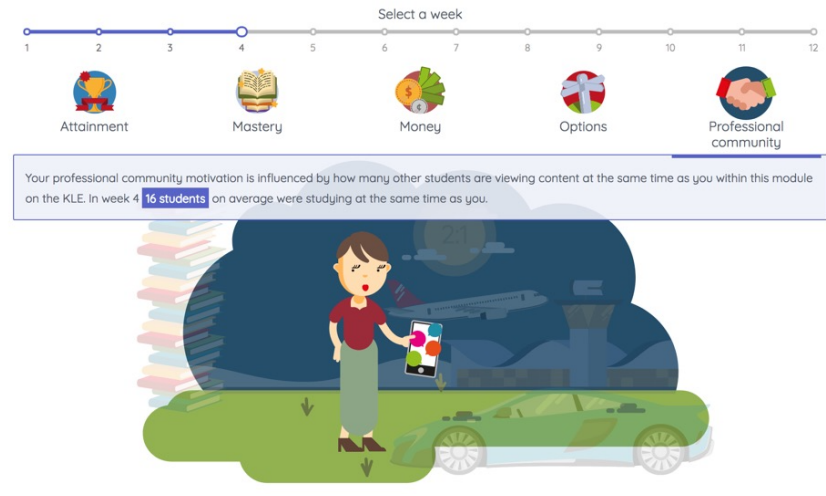

Figure 8: Final version of the "personified" theme showing 3 weeks' worth of data on the timeline. The visualization changes as the scores decrease. When a student interacts with a motivator they are given an explanation as to how the score was derived

Figure 9 shows an example Decision Tree that uses relevant features to predict the module "grade" 2 based on a student's VLE activity with particular resources, practicals (C_GRP_Practicals) and tutorials (C_GRP_Tutorials), as well as total number of VLE accesses to the module (ACC_TOT) and the time spent (ACC_DUR).

This model was then applied to current students, presenting their activity data back to them as weekly scores ${ }^{3}$, mapped to their chosen motivations and visualisation preference in the LA dashboard. The accuracy of these models was around $70 \%$ due to the relatively small sample that we were working with. Table 3 shows the mapping that was used to create scores for each motivator. This was produced following discussions with the module lecturers involved as to what features they felt best represent an individual motivator and the data available to us. For example, for "Mastery" of a subject, as well as the eventual grade being important, the variety and total amount of content that a student viewed on the VLE was

\footnotetext{
${ }^{2}$ The grade in this case used the degree classifications used in the UK. 1 st is $>70$ (class 5 in the figure), $2: 1$ is $>=60$ and $<=69$ (class 4 ) and so on

${ }^{3}$ We chose to use the data from each week in isolation i.e. matching the current week's data to the same week in delivery as the previous year
}

Table 2: Sources of data and final featureset

\begin{tabular}{|c|c|}
\hline Data Source & Feature \\
\hline $\begin{array}{l}\text { From VLE click } \\
\text { data }\end{array}$ & $\begin{array}{l}\text { Total number of content accesses } \\
\text { Total duration of content accesses } \\
\text { Average duration of content accesses } \\
\text { Number of days per week content is ac- } \\
\text { cessed } \\
\text { Average length of time between content ac- } \\
\text { cesses } \\
\text { Average group size of simultaneous content } \\
\text { accesses } \\
\text { Number of times specific content is accessed } \\
\text { Number of clicks on content of a certain } \\
\text { type } \\
\text { Number of clicks grouped by parent folder } \\
\text { Seen/unseen content }\end{array}$ \\
\hline $\begin{array}{l}\text { From lecture } \\
\text { capture data }\end{array}$ & $\begin{array}{l}\text { Total number of lecture capture views } \\
\text { Number of times specific lectures are } \\
\text { viewed }\end{array}$ \\
\hline From SITs data & $\begin{array}{l}\text { Module Grades } \\
\text { Absences (from practicals and lectures) }\end{array}$ \\
\hline
\end{tabular}

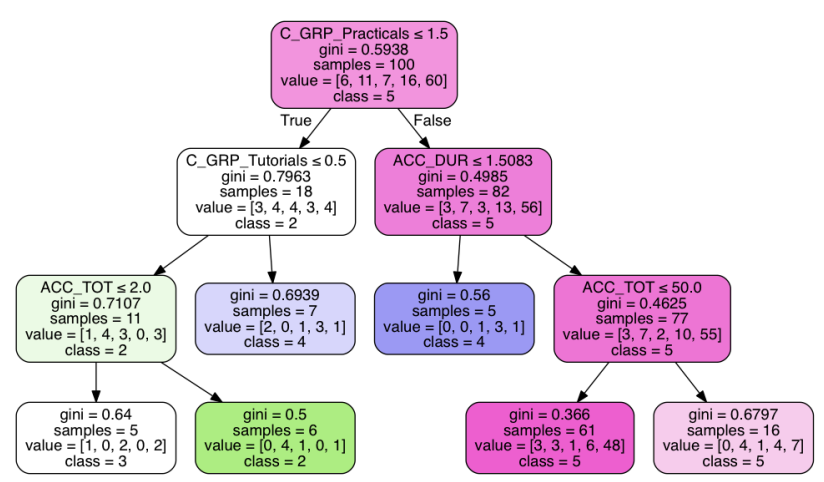

Figure 9: Weekly Decision Tree to predict grade 
Table 3: Feature mapping used to create scores for each motivator

\begin{tabular}{ll}
\hline Career/Industry & Grade, Absences, Total clicks \\
\hline Money & Grade, Absences, Total clicks \\
\hline Attainment & Grade \\
\hline Mastery & $\begin{array}{l}\% \text { of content seen, Grade, Variety of } \\
\text { content clicked }\end{array}$ \\
\hline Options & Grade, Absences, Total clicks \\
\hline Professional community & Simultaneous users \\
\hline Family & Grade, Absences Total clicks \\
\hline Self-development & $\begin{array}{l}\text { Total clicks, Total duration, Variety of } \\
\text { content clicked }\end{array}$ \\
\hline Fear of failure & Absences, $\%$ of content seen \\
\hline
\end{tabular}

also seen as an important factor; for "Money", "Career/Industry", "Options" and "Family" it was felt that all of these relate to future career prospects and therefore the final module mark, the number of absences from lectures/practicals and the total level of interactivity with the VLE was important; for "Attainment" students were simply shown their predicted grade.

Weekly recommendations were also produced based on statistics related to the data features computed each week (see Figures 6 and 8). The recommendations provided for each student are determined by the statistics that are below average (averaged over the cohort). For example, if the number of clicks in the 'Lectures' folder is below average for a particular student, a recommendation would appear showing them that they should "Read/review more of the resources in the 'Lectures' folder". Recommendations related to a maximum of 3 statistics showing the greatest negative percentage difference from the average are shown to each student each week. Using the models produced by the Decision Trees was also considered i.e. analysing the nodes and inputs to identify how class decisions were made, but it was determined that this approach needed further investigation before accurate recommendations could be made.

\section{INTEGRATION INTO DELIVERY}

The LA dashboard was successfully used on 2 undergraduate modules (Computer Science and Geography) in Semester 12017 with 94 students (52\%) signing up to the service ${ }^{4}$. A number of enhancements were then identified (described in section 2.3) and this feedback was then fed into the next version of the LA system which was integrated into the delivery of two modules in Semester 2 (both Computer Science), with a further 75 student sign-ups (44\%). Students were introduced to LA and the dashboard in the first lectures of each module and encouraged to ask questions and given time to sign-up, mainly via their mobile phones. Further reminder emails were sent in the first few weeks.

\footnotetext{
${ }^{4}$ Automatic enrolment on the system was not possible due to GDPR considerations and informed consent being needed for the use of their data for this purpose
}
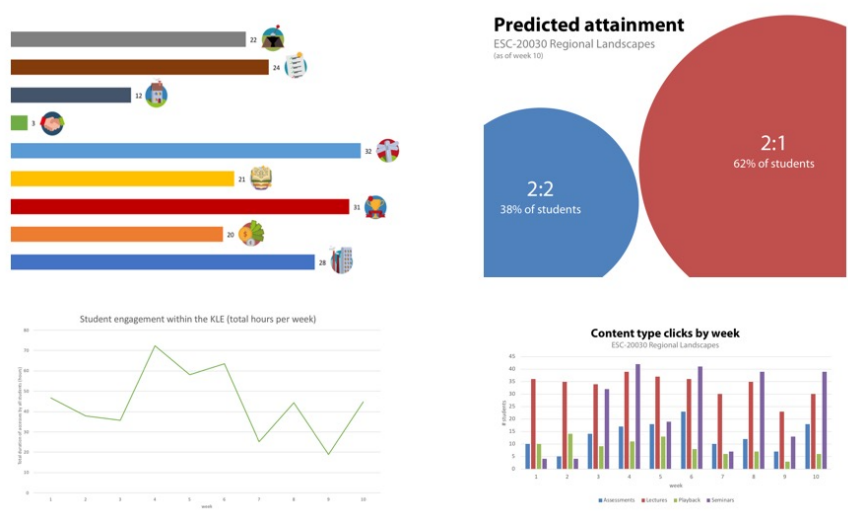

Figure 10: Example set of visualisations used as slides in lectures

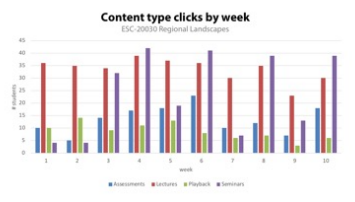

Weekly scores for each student were then generated (for all motivators), an email sent out with these scores (indicating whether scores had gone up or down) and the dashboard updated to show that week's scores, visualisations and recommendations.

In the first few weeks, although the LA tool often picked out users who were struggling or excelling, it became clear that embedding the lecturer in the LA process (by looking at weekly student VLE activity and the predicted grades before being made available to the students via a basic Lecturer-facing Dashboard created for this purpose) was important to identify where the model was underperforming and to make appropriate adjustments or changes to the feedback given to individual students (i.e. Lecture-in-the-Loop analytics). This often meant providing interventions in the form of personalised text in the weekly emails, advising a student about who they should contact for further support e.g. if they had not logged in to the VLE and/or missed all practicals/lectures.

In order to try and complete the LA loop and bring LA back into the classroom, an attempt was made on some modules to produce a set of visualisations (as slides) for the lecturer to use at the start of a lecture to promote discussion with students about which resources were being used or not used, the motivators chosen by the class and their current progress as a cohort (see Figure 10).

\section{EVALUATION}

At the end of Semester 2, an evaluation of the system was completed using a mixed methods approach: an online User Experience Questionnaire (UEQ), an analysis of the usage data of the LA tool and contextual interview session. Following the recommendations by [9] we attempted to evaluate not only the goals of the dashboard but also the impact on learners' motivation, as well as the usability of the tool. We also looked into whether learners understood the data and how much they agreed with it and how they interpreted it. Although we did not explicitly use the Evaluation Framework for Learning Analytics (EFLA-4) [20] similar questions related to "Awareness and Reflection" and "Impact" were included in the UEQ and the Contextual Interviews. The following sections detail the initial results from each. 


\subsection{User Experience Questionnaire}

The UEQ was based on the questionnaire developed by [12] which measures the User Experience of interactive products using classical usability aspects (efficiency, perspicuity, dependability) and user experience aspects (originality, stimulation). Additional questions related specifically to the LA tool were included such as whether a decline in weekly score would influence behaviour in following weeks, whether the data presented accurately reflected their engagement and if the tool could help to improve grade performance. In total 35 students completed the questionnaire.

The perspicuity (how easy it is to become familiar with a product) of the dashboard is good compared to other "products", with novelty (relating to how innovative and creative a product is), attractiveness and efficiency being above average. Students rated the dashboard as having below average levels of dependability (relating to whether the user feels in control of the interaction) which may relate to free-text comments from students wanting more information about how the scores are calculated and also that only $49 \%$ of students believed the data that is presented in the dashboard accurately reflected their engagement.

$80 \%$ of students said that a decline in their weekly score would or maybe influence their behaviour in the following weeks e.g. "I tend to get lazier as the semester goes on, having a reminder that I am actually doing less work is good.”. $77 \%$ felt that they could or maybe use the system as a tool to allow them to improve their grade performance e.g. "Tells me what I'm doing and what I can do to improve", "Gives a clear idea on what you need to do more of when studying”.

\subsection{Usage Data}

LA students across all modules showed increased engagement with the module compared to students from the previous year's cohort by clicking more in the VLE (between $4 \%$ and $20 \%$ more on the 4 modules) and with improved attendance (50\% - 100\% decrease in absences). Students showed improved engagement with version 2 of the tool over version $1.87 \%$ and $89 \%$ of students on semester 2 modules logged into the dashboard at least once vs $71 \%$ and $74 \%$ in semester 1 . Almost all students checked the weekly email at least once in semester 2 .

Overall engagement with the dashboard on some modules on a weekly level was perhaps initially disappointing (some modules only received an average of $20 \%$ of LA users looking at the dashboard each week). However, students were also able to engage with their LA via the weekly emails (which had higher weekly views $49 \%-72 \%$ ) which may have contributed to this. On average, per week, $51 \%$ of students viewed the email, $53 \%$ of students (who viewed the email) clicked through to the dashboard on the VLE and $22 \%$ of students viewed the dashboard directly. It should be noted that on the Geography module there was much higher levels of engagement where $72 \%$ of students viewed the email each week and $80 \%$ of those students then clicked through to see the full LA dashboard.

For the choice of themes, $59 \%$ of students chose the personified and $41 \%$ the professional representation. For the motivators, career (73\%) and money (68\%) were the most popular choices amongst all students with professional community the lowest (9\%).

\subsection{Contextual Interviews}

Finally, 7 one-on-one contextual interview sessions were completed with students to assess their metacognition of their use of the LA dashboard and email. The student was given access to their own dashboard during the interview session to help inform their responses and so they did not have to rely on memory. The sessions were recorded and summaries of answers to each question are given below.

Q. Before using the system, were you aware of your engagement with the VLE and your attendance?

Most students were aware of attendance but not VLE data.

Q. Can you describe your understanding of how you can influence the outcome of your learning analytics? How would you improve?

All students said that viewing more content/regular VLE interaction and attending more sessions would improve scores.

Q. What information have you found most useful when using the learning analytics system?

Answers varied but the number of clicks and the cohort comparison was mentioned frequently along with the scores' description, the content seen and the weekly timeline.

Q. What information have you found least useful when using the learning analytics system?

Most students were unsure about the accuracy of the grade predictions and weekly "swings" in prediction.

Q. Can you describe how the learning analytics system impacted your motivation?

It made most students reflect on a weekly/regular basis instead of only working hard around assessment time. When they saw their scores go down, it made them want to improve their grade and gave them an extra boost (although one student said "Seeing high scores during the middle of the semester incentivised them to 'cruise'."). It also made them keener to visit the VLE and look around to see missed content to make themselves a better student. It also reinforced effort e.g. "good seeing how making an effort yielded good results for a specific week, showing that if you put the effort in, you would likely perform better".

Q. How has the learning analytics system changed your awareness of your progress?

Students mentioned having feedback throughout the semester means that they do not have to wait until the end of the module. The lecturer visualisation slides that were shown in class were useful as it made them aware of resources that they hadn't looked at. They also mentioned that being able to compare their activity to the cohort was useful and seeing a drop in performance on the dashboard "kick-started" them to do more. e.g. "Without a system like this, although I would maybe know I wasn't engaging as much as I should, I probably wouldn't act on it".

Q. In general, do you feel that the learning analytics system has had a direct effect on your performance on the module? How?

Most students said positive (although "slightly") and mentioned that it would have more impact on "harder" modules.

\section{DISCUSSION}

The main aim of the project was to give students access to personalised feedback and support in real-time via LA, using a form of representation that goes beyond traditional forms of visualisation. 
The novel UCD approach used has achieved this by creating a set of motivational metaphors that relate to reasons why students want to study in HE and visualised these with two themes, based on student feedback. The tool has then been trialled on 4 UG modules with 169 sign-ups to the tool and although not quite in real-time (due to the data available), students have been given weekly indicators of their progress and recommendations for improvement and support where needed. Considering the conclusions made by [2] related to the sparsity of work related to student facing LA systems including some form of user needs assessment, a discussion of the visual or recommendation design process and a usability test on the system, we believe that this work has tackled a number of those issues, and made a clear contribution in this area.

The evaluation has shown that students' feelings of dependability and trust of the underlying analytics and data is variable. This however is to be expected as a number of disclaimers were included in the system as to the accuracy of the predictions and also the scores for the motivators were limited by the data available. However, we believe that as more data is made available as part of the continued push for metrification of HE in the UK (and Worldwide), there is the opportunity to incorporate more appropriate data sources into a system like this, making the mapping between motivators and features more realistic and not limited by the pragmatic nature of our current motivator/data associations. For example, at the moment the score for "Money" is simply based on a combination of Grade, Absences and Total clicks (a proxy for potential career success). The incorporation though of Longitudinal Educational Outcomes data [7] which shows how much money UK graduates of different courses at different universities earn could make this score predictor actually relate to an indication of future salary. From conversations with the careers service at the University, views of careers advice materials or appointments made with careers counsellors via the online careers' hub could be incorporated into the "Career" and "Self-development" motivators. It is important to realise though that students will be sceptical about systems like this and will need reassurance as to their accuracy, how predictions are determined and how their data is used.

With regards to the usability and interface design of the system, students were mostly positive. Although most scores were only "above average" or "good" on the UEQ, we believe that this was negatively impacted by the fact that the LA Dashboard itself had to be integrated within the module page of the VLE, which itself has a number of usability issues, particularly on mobile devices.

With regards to usage and engagement, it was good to see that there was an increase in overall VLE activity compared to the previous cohort average. This could be partially explained by the selfselecting nature of students that signed-up for the project though i.e. already being engaged and motivated, and further analysis is needed to see how representative this sample is. It should also be noted that although the benefits of LA were explained to students, it is perhaps surprising that the overall sign-up rate was $48 \%$. This may indicate that not all students want LA. Engagement with the tool itself was varied but almost all students once signed-up did interact with either the email or the dashboard at least once. Again, the integration within an individual modules' VLE homepage (requiring a number of clicks after login to see the dashboard) probably affected this and a degree programme level LA dashboard, shown on login to the VLE would be the preferred method of delivery (and what was found by [3] and recommended by [9]). Unfortunately, in this instance, access to this level of integration with the live VLE was not possible. Although true benchmark usage levels and behaviour for student-facing LA have not yet been determined, compared to one of the most mature systems in the UK at Nottingham Trent University [6] who report an average of 13 logins per student over the year [5], the usage levels for our system are actually quite promising. The module which had the greatest number of sign-ups and highest levels of weekly engagement was in Geography. Interestingly, it was this module where the in-class visualisations were used most and also where the VLE plays a significant part of the delivery of the module. There is also the possibility that for the other modules, all Computer Science, there is a more cautious approach to technologies like this (counter-intuitive perhaps to what would be expected) due to students being more digitally literate and privacy aware. More work is needed to see what differences in student perceptions of LA there are in different disciplines but embedding both the lecturer and the physical lecture into LA seems to be important. When it comes to the issue of students who signed-up generally ignoring the privacy policy, this is a common problem with privacy policy reading behaviour [15] and at this point has been identified as a future refinement. Ideally though, LA would be integrated into the institutional I.T. Policies and Procedures, meaning that consent would be gained as part of University enrolment.

Finally, and most pleasing, was that during both the UCD process and the final evaluation, most students could see how the LA system could support their learning and, in some cases, this has had a direct impact on their levels of engagement. The weekly feedback was appreciated and the recommendations, although quite basic, were often acted upon. Seeing a change in scores, did seem to motivate most students and an interesting bi-product for some was that having a weekly progress indicator made them work more consistently, as opposed to leaving work until the end of the module. Further analysis however is need to try and quantify this effect e.g. comparing their outcomes on these modules with their overall profile. Also, the fact that the majority of students did choose the "personified" view does indicate that different forms of visualisation will be accepted and perhaps preferred by students, particularly if they represent things that are personal to their lives and aspirations. We believe that this also helps to bridge the mismatch between the LA design and/or interface and the capacity of users to engage with the platform (identified by [10]).

\subsection{Key Contributions and Lessons Learned}

The main contribution of this paper is a description of one of the first uses of a UCD approach for Student Facing LA that has produced forms of representation, recommendation and interaction design that go beyond those used in current similar systems (which tend to use traditional visualisation methods, student target setting and logging self-declared activity i.e. the fitbit model [16]). It also shows that this new form of LA personalisation would motivate students and impact their learning behaviour. The key message therefore is that working with students to create LA systems, using approaches that go beyond standard focus groups, produces a 
more personalised and potentially engaging form of LA. Although this gap has been identified previously by [2], there needs to be a greater emphasis on fully utilising the UCD process, not just for initial requirements gathering, so that the design and development process of Student Facing LA systems is fully transparent, from the initial analysis stage all the way to final evaluation. Without this transparency, comparison of LA systems and development approaches will be inconsistent and an evidence base for Student Facing LA hard to compile.

During this process we have also learned a number of lessons we feel are useful for researchers and practitioners in this area including:

- UCD is based on the ability to access users and so the use of student ambassadors is incredibly helpful. The response rates and variety of students that signed up for the user research sessions would have been far more limited without them.

- It is important to introduce LA systems to students in the context of their learning i.e. in-class, to maximise buy-in and to answer questions and discuss concerns.

- Similarly, it is important to integrate LA into in-class delivery e.g. by using visualisations at the start of sessions to help bridge the gap between in-class, VLE and LA engagement.

- Complete automation of Student Facing LA systems is dangerous (particularly with small data sets) and the lecturer must be kept in the loop and interpret the analysed data before releasing it to students.

- Students will only engage with a system if they trust the data and understand how "scores" are calculated.

- Not all students will initially want LA (or realise its usefulness) and those that do will want different things. Personalisation of LA is therefore very important.

\section{CONCLUSIONS}

The process of involving students when developing Learning Analytics systems, and in fact any digital services, is vital. Although time consuming, without getting direct feedback from students, the design and evaluation of this particular system would have been significantly different. It is also important to complete the LA loop by making sure that lecturers are part of the system and seeing how they can embed it into their own practice. There is still a great deal of work to do, to find out how students want to interact with LA. It is clear though that working with them to answer these questions will not only help align their needs and expectations but also make sure that we are producing systems that students actually want to use, not just systems that we are hoping that they use.

\section{ACKNOWLEDGMENTS}

This research was supported by the HEFCE Catalyst Fund and Keele University. We would like to thank the student ambassadors for all of their work on the project and also all of the students who signed up to the system and were part of user research activities.

\section{REFERENCES}

[1] Kimberly E. Arnold and Matthew D. Pistilli. 2012. Course signals at Purdue. In Proceedings of the 2nd International Conference on Learning Analytics and
Knowledge - LAK '12. ACM Press, New York, New York, USA, 267. https: //doi.org/10.1145/2330601.2330666 arXiv:0709.1706v2

[2] Robert Bodily and Katrien Verbert. 2017. Trends and issues in student-facing learning analytics reporting systems research. In Proceedings of the Seventh International Learning Analytics \& Knowledge Conference on - LAK '17. ACM Press, New York, New York, USA, 309-318. https://doi.org/10.1145/3027385.3027403

[3] Ed de Quincey, Mark Turner, Nikki Williams, and Theocharis Kyriacou. 2016. Learner Analytics ; The Need for User-Centred Design in Learning Analytics. ICST Transactions on Ambient Systems 3, 9 (aug 2016), 6-9. https://doi.org/10. 4108/eai.23-8-2016.151643

[4] Mollie Dollinger and Jason M. Lodge. 2018. Co-creation strategies for learning analytics. In Proceedings of the 8th International Conference on Learning Analytics and Knowledge - LAK '18. ACM Press, New York, New York, USA, 97-101. https: //doi.org/10.1145/3170358.3170372

[5] Ed Foster. 2018. The NTU Student Dashboard - implementing a University wide learning analytics system. https://www.slideshare.net/edfosterntu/ able-the-ntu-student-dashboard-university-of-derby

[6] Rebecca Ferguson, Mike Sharkey, and Negin Mirriahi. 2016. Practitioner Track Proceedings of the 6th International Learning Analytics \& Knowledge Conference (LAK16). (2016), 14-15.

[7] Gov.uk. 2018. Graduate outcomes for all subjects by university. https://www.gov.uk/government/statistics/ graduate-outcomes-for-all-subjects-by-university

[8] Dennis N Hinkle. 1966. The change of personal constructs from the viewpoint of a theory of construct implications. Ph.D. Dissertation.

[9] Ioana Jivet, Maren Scheffel, Marcus Specht, and Hendrik Drachsler. 2018. License to evaluate. In Proceedings of the 8th International Conference on Learning Analytics and Knowledge - LAK '18. 31-40. https://doi.org/10.1145/3170358. 3170421

[10] Kirsty Kitto, Sebastian Cross, Zak Waters, and Mandy Lupton. 2015. Learning analytics beyond the LMS. In Proceedings of the Fifth International Conference on Learning Analytics And Knowledge - LAK '15. ACM Press, New York, New York, USA, 11-15. https://doi.org/10.1145/2723576.2723627

[11] Richard A Krueger. 2002. Designing and conducting focus group interviews. University of Minnesota (2002), 17. https://doi.org/10.1136/bmj.311.7000.299 arXiv:8Fournier.RELATIONSHIPbrand-1998

[12] Bettina Laugwitz, Theo Held, and Martin Schrepp. 2008. Construction and evaluation of a user experience questionnaire. In Lecture Notes in Computer Science (including subseries Lecture Notes in Artificial Intelligence and Lecture Notes in Bioinformatics), Vol. 5298 LNCS. Springer, Berlin, Heidelberg, 63-76. https://doi.org/10.1007/978-3-540-89350-9-6

[13] Phil Long and George Siemens. 2011. Penetrating the Fog: Analytics in Learning and Education. Technical Report. https://er.educause.edu/\{ $\} /$ media/files/ article-downloads/erm1151.pdf

[14] Leah P. Macfadyen and Shane Dawson. 2010. Mining LMS data to develop an "early warning system" for educators: A proof of concept. Computers and Education 54, 2 (feb 2010), 588-599. https://doi.org/10.1016/j.compedu.2009.09.008

[15] Jonathan A. Obar and Anne Oeldorf-Hirsch. 2016. The Biggest Lie on the Internet: Ignoring the Privacy Policies and Terms of Service Policies of Social Networking Services. SSRN Electronic fournal (jun 2016). https://doi.org/10.2139/ ssrn.2757465

[16] Paul Bailey. 2018. Jisc learning analytics service core slides. https://www. slideshare.net/paul.bailey/jisc-learning-analytics-service-core-slides

[17] Keith Perry. 2014. New IT system will identify failing university students Telegraph. https://www.telegraph.co.uk/education/educationnews/10805717/ New-IT-system-will-identify-failing-university-students.html

[18] Gordon Rugg. 2013. Laddering : An introduction. Technical Report. www. hydeandrugg.com

[19] Gordon Rugg and Peter McGeorge. 1995. Laddering. Expert Systems 12, 4 (nov 1995), 339-346. https://doi.org/10.1111/j.1468-0394.1995.tb00271.x

[20] Maren Scheffel. 2017. Evaluation Framework for Learning Analytics. http: //www.laceproject.eu/evaluation-framework-for-la/

[21] Beat A. Schwendimann, María Jesús Rodríguez-Triana, Andrii Vozniuk, Luis P. Prieto, Mina Shirvani Boroujeni, Adrian Holzer, Denis Gillet, and Pierre Dillenbourg. 2016. Understanding learning at a glance. In Proceedings of the Sixth International Conference on Learning Analytics \& Knowledge - LAK '16. ACM Press, New York, New York, USA, 532-533. https://doi.org/10.1145/2883851.2883930

[22] Niall Sclater, Alice Peasgood, and Joel Mullan. 2016. Learning Analytics in Higher Education A review of UK and international practice Full report. Technical Report. https://www.jisc.ac.uk/sites/default/files/learning-analytics-in-he-v3.pdf

[23] Katie Sherwin. 2018. Card Sorting: Uncover Users' Mental Models for Better Information Architecture. https://www.nngroup.com/articles/ card-sorting-definition/

[24] U.S Department of Health \& Human Services. 2018. User-Centered Design Basics | Usability.gov. https://www.usability.gov/what-and-why/ user-centered-design.html 